\title{
Neuroscientific Approaches to Self-Regulatory Control in Sports
}

\author{
Wanja Wolff ${ }^{1,2}$, Anna Hirsch ${ }^{1}$, Maik Bieleke ${ }^{3,4}$, \& Amitai Shenhav ${ }^{5}$ \\ ${ }^{1}$ Department of Sport Science, University of Konstanz, Germany \\ ${ }^{2}$ Department of Educational Psychology, University of Bern, Switzerland \\ ${ }^{3}$ Department of Psychology, University of Konstanz, Germany \\ ${ }^{4}$ Department of Psychology, University of Vienna, Austria \\ ${ }^{5}$ Cognitive, Linguistic, \& Psychological Sciences, Brown University, Providence, RI, USA
}

Chapter to appear in: C. Englert and I. Taylor (Eds). Handbook of Self-regulation and Motivation in Sport and Exercise. Routledge.

Author version 15/09/20.

Please do not circulate or cite without author's permission. 


\section{Introduction}

Sports performance critically depends on physical fitness and skill level. However, success also hinges on how well athletes deal with psychological obstacles that threaten optimal performance (e.g., Wolff, Bieleke, \& Schüler, 2019). For example, in order to make a critical free-throw, basketball players have to ward off challenges to effective movement execution, triggered both externally (e.g., distraction by hostile chants) and internally (e.g., fear of failure). In the same vein, cyclists whose muscles are aching need to overcome their automatic inclination to ease up and slow down. These exemplary challenges are well within the scope of current definitions of self-regulatory control ${ }^{1}$ as the "efforts people exert to stimulate desirable responses and inhibit undesirable responses" (de Ridder, Lensvelt-Mulders, Finkenauer, Stok, \& Baumeister, 2012, p. 77) or "the set of mechanisms required to pursue a goal, especially when distraction and/or strong (e.g., habitual) competing responses must be overcome" (Shenhav, Botvinick, \& Cohen, 2013, p. 217). Thus, it seems plausible that, in addition to fitness and skill, sports performance hinges on the successful exertion of mental effort in the service of selfregulatory control.

Indeed, a large body of research has found support for the importance of self-regulatory control in sports (Englert, 2016), both at the trait level (i.e., stable self-regulatory tendencies within an individual) and the state level (i.e., situationally-defined influences on one's tendency to self-regulate). For instance, on the trait level, one study has shown that elite cyclists outperform non-elite peers in a reaction-time based measure of trait self-control (Martin et al., 2016). In another study, youth athletes in an elite talent development program scored higher on a self-report measure of self-regulatory control than their non-selected peers (Wolff, Bertrams, \& Schüler, 2019). In the recreational context, high self-regulatory control has been linked with better adherence to exercise regimens (Stork, Graham, Bray, \& Martin Ginis, 2016). This makes intuitive sense, as self-regulatory control has been shown to help people deal with the difficulties of adhering to valued behaviors (Wolff, Martarelli, Schüler, \& Bieleke, 2020). At the state level, the application of self-regulatory control detrimentally affects subsequent sports performance (for a meta-analysis, please see Giboin \& Wolff, 2019; but see also Holgado, Troya, Perales, Vadillo, \& Sanabria, 2019). For example, impaired performance after prior self-regulatory control has been found in such diverse sport settings as sprint-running (Englert, Persaud, Oudejans, \& Bertrams, 2015) and dart throwing (Yang, Park, \& Shin, 2019). Finally, it has been shown that physical effort causes feelings of mental exertion, impairs self-regulatory control and leads to hypoactivations in control-relevant areas of the brain (Blain et al., 2019; Wolff, Schüler et al., 2019). This is consistent with the claim that physical performance requires self-regulatory control.

A multitude of theoretical accounts have been proposed that specify why and when self-regulatory control is applied and why it sometimes appears to fail (e.g., Beedie \& Lane, 2012; Inzlicht, Schmeichel, \& Macrae, 2014; Kotabe \& Hofmann, 2015; Kurzban, Duckworth, Kable, \& Myers, 2013; Shenhav et al., 2013). In particular, recent years have seen substantial advancements in our understanding of the guiding principles of self-regulatory control, as well as the neuronal structures that orchestrate its allocation (Munakata et al., 2011; Holroyd \& Yeung, 2012; Cavanagh \& Frank, 2014; Shenhav et al., 2017). In the present chapter, we will demonstrate how these developments can inform and advance neuroscientific research on self-regulatory control in sports. In part one of this chapter, we will follow recent mechanistic approaches and conceptualize self-regulatory control as a reward-based decision. Specifically, we introduce the expected value of control (EVC) theory (Shenhav et al., 2013) as a mathematically explicit framework that provides a value-based computational expression for the allocation of self-regulatory control and that specifies the mechanistic foundation of self-regulatory control.

\footnotetext{
${ }^{1}$ Sometimes also referred to as self-control or cognitive control.
} 
In part two of the chapter, we will discuss recent technological advancements that have enabled neuroscientific research even during full body movements, an important prerequisite for investigating neural processes during sports performance (Ekkekakis, 2009; Perrey \& Besson, 2018). This has enabled researchers to satisfy recent calls to investigate the "sporting brain" (Walsh, 2014, R859) and to examine whether findings from basic cognitive neuroscience can be applied to the field of sports and exercise. We will summarize neuroscientific research in sports through the lens of self-regulatory control, with a specific focus on functional near-infrared spectroscopy (fNIRS) as a neuroscientific method that appears to be particularly suited for research in sports.

\section{Computational and mechanistic operating principles of self-regulatory control}

In this section, we will elaborate on the concept of mental effort and why it is central to the definition of self-regulatory control. We will then introduce a mechanistic account of the processes that guide the allocation of mental effort in the service of self-regulatory control, based on the EVC theory.

\section{Self-regulatory control is effortful and costly}

In keeping with this chapters' focus on physical performance, we will use an analogy from physical effort to aid the definition of mental effort. Assume, for instance, that a marathon runner is able to run a marathon in 02:08:00h (i.e., capacity). To qualify for the Olympics, he needs to run it in < 02:11:30h (i.e., task characteristics). Physical effort is what mediates between his running capacity and the time that is required for qualification, on the one hand, and the ultimately achieved finishing time, on the other hand. Likewise, mental effort can be conceptualized as that which "mediates between (a) the characteristics of a target task and the subject's available information-processing capacity and (b) the fidelity of the information-processing operations actually performed, as reflected in task performance" (Shenhav et al., 2017; p. 100). Self-regulatory control is believed to be the force through which mental effort is exerted (Shenhav et al., 2017). Tasks vary in the degree to which they can rely on controlled versus more automatic processes (Posner \& Snyder 1975; Schneider \& Shiffrin, 1977). One of the major factors that can determine the control requirements of a task is the extent to which pursuing the task goal requires the individal to overcome more automatic (e.g., default) responses (Cohen et al., 1990; Shenhav et al., 2013). To illustrate, when the runner is hurting, the automatic response tendency would be to stop. However, to qualify for the Olympics, this response needs to be controlled. Thus, although in this case the behavioral output relies on physical effort (e.g., engagement of locomotor muscles), self-regulatory control (and therefore mental effort) is needed to override the automatic response tendency of stopping or slowing down.

Although it is often crucial for success, people tend to avoid engaging in self-regulatory control because the mental effort required (and associated experiences of fatigue and frustration; Wolff, Sieber, Bieleke, \& Englert, 2019) is experienced as aversive (Kool \& Botvinick, 2018; Westbrook \& Braver, 2015; see also Box 1). Thus, applying self-regulatory control appears to carry an intrinsic disutility (Kool \& Botvinick, 2018). Accordingly, people tend to mobilize effort only if the goal is subjectively worth it (Gendolla \& Richter, 2010) and not to a greater degree than is warranted by the difficulty of a given task (Wright, Mlynski, \& Carbajal, 2019). This indicates an aversion against mobilizing more effort than necessary (Richter, Gendolla, \& Wright, 2016). Returning to the example of the marathon runner: If the only goal is to qualify for the Olympics (i.e., no other incentives like winning the race or beating a rival are present), he should only run as fast as needed to qualify. This reasoning is in accordance with a large body of research showing that people try to conserve their resources when it comes to the mobilization of effort (Richter et al., 2016). Taken together, research suggests that self-regulatory control is treated as if it is costly and limited. 


\section{Box 1: When effort adds value}

Mental effort plays a key role in our understanding of self-regulatory control. An overwhelming body of research shows that mental effort produces costs that people generally try to avoid (Kurzban, 2016). Sports seems to be at odds with this law of least effort (Hull, 1943). For most sports, especially endurance sports like running or cycling, physical and mental effort are not only instrumental to reaching one's goal, they often constitute the goal itself - that is effort is often central to the sporting experience. To use the words of multiple Tour de France champion Greg LeMond: "it never gets easier, you just go faster" (Missel, 2017, para. 7). Yet, every year, millions of people pay considerable amounts of money to participate in running competitions with neither the chance nor the expectation of winning (Andersen, 2020). For most of them, the cost of participating in such events ranging from entry fees and costs for equipment and travel to the opportunity costs of training and the risk of suffering an injury (Maxcy, Wicker, \& Prinz, 2019) - seems disproportionate compared to what they receive in return. This makes it difficult to explain why so many people freely choose to participate in sporting competitions. Interestingly, one experience recreational athletes appear to seek out in a marathon, or an ultra-marathon might simply be the experience of pushing through perceived boundaries and still keep going (e.g., Finn, 2018).

As this example illustrates, some people engage in sports because it requires mental and/or physical effort and not despite of it (Loewenstein, 1999). This implies that effort (mental or physical) may in a certain case add value to an activity. From the perspective of the EVC framework, effort can add value in two different ways (Inzlicht, Shenhav, \& Olivola, 2018): First, it might amplify the value of the expected outcome. Thus, success is more rewarding when it is achieved with high effort and failure feels worse when one had invested a lot of effort. In the words of Brazilian soccer legend Pelé: "The more difficult the victory, the greater the happiness in winning" (Keville, 2015, para. 3). Second, effort itself might be intrinsically rewarding irrespective of the outcome. One possible explanation for this might be a phenomenon referred to as learned industriousness (Eisenberger, 1992): If athletes learn to directly associate effort with reward, the effort assumes the role of a secondary reinforcer. Indeed, athletes and their coaches often emphasize the need to make an effort, irrespective of the direct outcome. For example, golfer Arnold Palmer stressed that one should "always make a total effort, even when the odds are against you" (Park, 2013, para. 38). And the value of effort is very clearly expressed by Eddy Merckx - considered by many to be the greatest cyclist of all time - who stated that "when it's hurting you, that's when you can make a difference" (Alé La Merckx, 2018, para. 5). The paradoxical nature of effort as both costly and rewarding is not limited to experiences in the sports setting, and has recently started to receive research interest (for a review, please see Inzlicht et al., 2018), although comparatively little research has yet been conducted to investigate the ways in which effort adds value. Sports seems to be a domain where effort is held in very high regard and treated as an incentive in its own right. The field of sports and exercise thus serves as a prime target for the investigation of this effort paradox.

Various explanations have been proposed for why the capacity for self-regulatory control might be limited. For example, resource-based accounts suggest that self-regulatory control depletes a metabolic resource (see chapter 2 this volume; Baumeister, Bratslavsky, Muraven, \& Tice, 1998). In contrast to such structural limitations in the capacity for self-regulatory control, other accounts focus on the computational properties of the neuronal systems that govern control. From this perspective, exertion of self-regulatory control is perceived as effortful not because a resource has been depleted but to index the costs that arise in tasks that compete for the same neural representations (Feng et al., 2014; Musslick et al., 2016). This explanation can be transferred to the context of sports and exercise: If an athlete is applying self-regulatory control to perform at her best in a cycling time trial, performance in concurrent tasks that rely on control will likely be impaired (if performance is not 
impaired, then the task should at least be perceived as more effortful). For example, while the athlete has to control the impulse to go slower, a concurrent task that also relies on impulse control (e.g., to control one's emotional expression) would require self-regulatory control to manage both tasks concurrently, thereby leading to impaired performance and/or increased sensation of mental effort. Tentative support for this interpretation in the context of physical performance comes from the occurrence of cognitive motor interference that already occurs in simple motor tasks like walking (for a meta-analysis, please see Al-Yahya et al., 2011). Likewise, impaired cognitive performance in dualtask situations has been found in such diverse sport settings as table tennis (Schaefer \& Scornaienchi, 2020), swimming (Stets, Smith, \& Helton, 2019) or climbing (Darling \& Helton, 2014). For example, when participants were asked to perform a n-back task while returning table tennis balls from a ball machine, this led to impaired n-back performance (Schaefer \& Scornaienchi, 2020). Interestingly, this dual-task cost was signifcantly more pronounced in novices than in experts, which might point towards more automated processing of demands in experts (Schneider \& Shiffrin, 1977).

While the exact reasons that limit the brain's capacity for self-regulatory control are still debated (Kurzban et al., 2013; Shenhav et al., 2017), it appears to be clear that people invest mental effort sparingly and treat its mobilization as if the capacity for control is limited. Consequently, researchers have tried to understand the factors that determine how people choose to allocate self-regulatory control.

\section{The expected value of control theory}

Research on self-regulatory control in sports has long been dominated by resource-based conceptualizations of self-regulatory control (for an overview, please see Englert, 2016). Recently, these resource-based accounts have been challenged empirically (Carter \& McCullough, 2014; Hagger \& Chatzisarantis, 2016; Wolff, Baumann, \& Englert, 2018) as well as conceptually (Inzlicht et al., 2014; Kurzban et al., 2013) and recent theoretical accounts now converge towards conceptualizing selfregulatory control as some form of reward-based choice (Berkman, Hutcherson, Livingston, Kahn, \& Inzlicht, 2017; Inzlicht et al., 2014; Kool \& Botvinick, 2014; Kurzban et al., 2013; Wolff \& Martarelli, 2020). However, these theoretical accounts have so far rarely been adopted in research on selfregulatory control in sports and exercise. This is puzzling because reward-based accounts play an important role in research on motor control (Körding, Fukunaga, Howard, Ingram, \& Wolpert, 2004; Manohar et al., 2015; Morel, Ulbrich, \& Gail, 2017; Shadmehr, Huang, \& Ahmed, 2016), which is fundamental to any sporting activity. Here, we present the expected value of control (EVC) theory as one such reward-based model of self-regulatory control (Shenhav et al., 2013, Shenhav, Cohen, \& Botvinick, 2016). The EVC theory synthesizes core concepts of various control theories into an integrative framework that specifies the computational properties as well as the mechanistic underpinnings of self-regulatory control (for an illustration, please see Figure $1 \mathrm{~A}$ ).

\section{Computation of the EVC}

According to the EVC theory, people allocate self-regulatory control in a way that maximizes the expected payoff while minimizing the mental effort that is required. These collectively determine the expected value of a given control allocation (EVC). The outcome of this cost-benefit analysis (the EVC's of candidate control configurations) determines which task(s) are most worth allocating self-regulatory control to, and how much control should be allocated (Fig. 1B). Equation 1 formalizes how the EVC is calculated (Shenhav et al., 2013):

$$
\text { EVC }(\text { signal, state })=\left[\sum_{i} \operatorname{Pr}\left(\text { outcome }_{i} \mid \text { signal, state }\right) \cdot \operatorname{Value}\left(\text { outcome }_{i}\right)\right]-\operatorname{Cost}(\text { signal })
$$


The situation (denoted as state) a person applies control to is shaped by internal and external states the person finds itself in. For example, a marathon runner might face a strong headwind (external) and also have some lingering doubts regarding her stamina over the full distance (internal). In any given state, different potential control signals of varying vigor can be specified (Fig. 1A). The marathon runner's overall goal might be to qualify for the Olympic Games. To do so, she has to complete the distance faster than a set target time and this is likely to be very hard. Thus, while running, she has to control the automatic impulse to ease up and instead stick with her target running pace. Over the course of the competition, the effort required for sticking to the race pace will rise due to fatigue that is setting $\mathrm{in}^{2}$. The athlete might reason that she can only consistently resist the impulse to ease up as long as perceived physical exertion does not go beyond $80 \%$ of her maximum in the first half of the race, to avoid what runners refer to as "hitting the wall". Further, this might allow her to increase the intensity late in the race and produce a final spurt if needed. Control signals therefore vary in identity
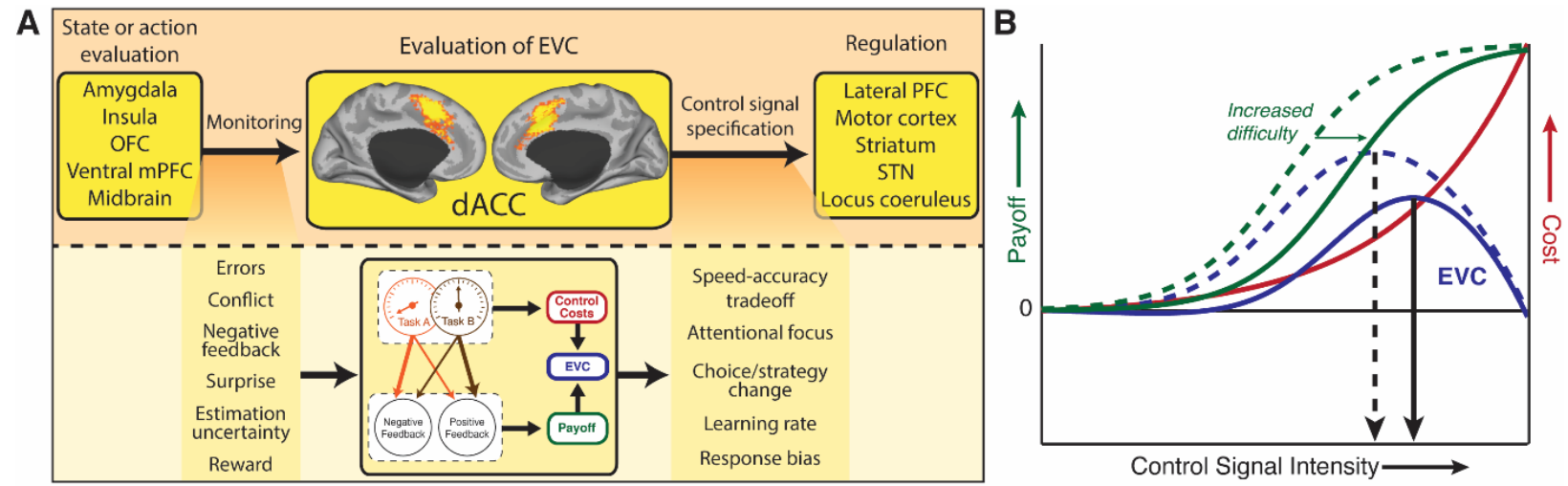

Figure 1. The Expected Value of Control (EVC) theory. (A) The EVC theory predicts that dACC integrates information about relevant incentives and task demand to determine the overall EVC of potential control configurations. On the basis of this EVC calculation, the dACC specified the optimal (EVC-maximizing) set of control signals, and signals these to relevant downstream regions which guide the execution of these control signals. Adapted from Shenhav et al. (2016). (B) Within the EVC framework, increases in the expected difficulty of a task (bold vs. dashed lines), will often lead to the prediction that additional control is needed to achieve a given level of payoff (green curves). This expected payoff is discounted by the expected cost (red curves) of exerting the necessary mental effort (control intensity), determining the overall EVC of that control intensity (blue curves). The maximum of this EVC curve determines the optimal control setting (black arrows). Adapted from Shenhav et al. (2013).

(e.g., "run" and "inhibit inclination to ease up") and in intensity (e.g., for running this might vary from $0 \%$ to $100 \%$ of maximum effort).

EVC can be calculated for any available configuration of control signal identities and intensities. As can be seen in the right part of Equation 1, the EVC of any given control signal configuration is comprised of two main components: an expected payoff and a cost. The expected payoff is determined by considering potential future outcomes that are relevant to one's task - including potential praise and pride that come with success, and potential admonishment and embarrasment that come with failure - and weighing these potential outcomes by the likelihood that they would occur under a particular control setting. For instance, as someone increases their physical exertion, they increase the likelihood of success (and attendant positive incentives) and decrease the likelihood of failure (and attendant negative incentives). However, increasing physical exertion is also costly: all things being equal, exercise at very high intensities (e.g., $95 \%$ of maximum) generally elicits a more negative affective response than exercise at lower intensity (e.g., 80\% of maximum) (e.g., Ekkekakis, Parfitt, \& Petruzzello, 2011; Roloff et al., 2020). This cost is accounted for by the final term in the equation, which

\footnotetext{
2 Indeed, research indicates that perceived exertion, rather than physiological resource depletion (e.g., locomotor muscle fatigue), might be the signal that ultimately leads to the termination of an exercise (e.g., chapter X, this volume; Marcora, Staiano, \& Manning, 2009; Staiano, Bosio, de Morree, Rampinini, \& Marcora, 2018).
} 
trades off against the expected payoffs, discounting the potential positive outcomes that accrue from increasing intensities of physical exertion. As can be inferred from Equation 2,

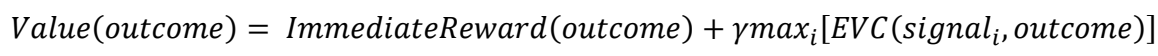

(Equation 2)

the outcome value reflects the value of the immediate change that occurs due to applying selfregulatory control (denoted as ImmediateReward), as well as accounting for the EVC of future control signals that are feasible based on the chosen signal (expressed as a maximization of EVC taking into account feasible control signals). This recursive definition of outcome value is important, because it highlights that the chosen EVC is not only maximized based on the immediate reward but also on the value of more distal states. For example, the ImmediateReward of running only at $80 \%$ of maximum exertion might in fact be negative, because the athlete will run slower than at $95 \%$ of maximum exertion and this might lead to the athlete being dropped from the lead group. However, specifying a control signal of such (comparably) little intensity might allow this athlete to maintain the target pace over the full distance, better positioning her to achieve her goal of qualifying for the Olympics. Thus, the value of an outcome is the sum of proximal and distal changes that are brought about by the specified control signal. However, as humans prefer immediate rewards over future rewards (Critchfield \& Kollins, 2001; Frederick, Loewenstein, \& O'Donoghue 2002), a discounting factor $\gamma$ is introduced to discount the impact of future EVCs in determining the overall value of the outcome that is achieved by the current control signal. This discounting factor is a variable ranging from zero to one to account for intra- and inter-individual differences in discounting. Interestingly, a large-scale analysis of 1.7 million recreational runners' pacing strategies showed that relatively fast starts and fast finishes were both predictors of poor overall performance (Smyth, 2018). From an EVC perspective, this might be attributed to a suboptimal discounting factor (i.e., by over- or underweighting future EVCs).

EVC theory proposes that the human control system performs these calculations, compares the EVCs for different control signals and then selects the one where EVC is maximized. Recent work has validated these predictions by showing that simulated agents that are designed to maximize their EVC adjust their task performance based on the incentives and task demands in similar ways as has been observed in empirical studies of motivation and self-regulatory control (Musslick, Shenhav, Botvinick, \& Cohen, 2015; Lieder et al., 2018; Bustamante, Lieder, Musslick, Shenhav, \& Cohen, 2020, 2020).

\section{Mechanistic underpinnings of self-regulatory control}

In addition to specifying the computational properties that underlie self-regulatory control, EVC theory also specifies candidate neural structures that mediate different processes involved in allocating and adjusting self-regulatory control (Shenhav et al., 2013). EVC theory delineates three core functions: Specification, Regulation and Monitoring. Self-regulated control consists of a continuous loop in which control signals are specified, applied, and the outcome is monitored to assess whether the control signal needs to be adjusted. EVC theory proposes that the dorsal anterior cingulate cortex (dACC) sits at the interface of monitoring and specification, whereas regulation is primarily mediated by regions downstream of $d A C C$ that execute specific types of self-regulatory control, such as the lateral prefrontal cortex (IPFC). The functions EVC theory ascribes to dACC and IPFC are well supported by a large body of research (for reviews, please see Badre, 2008; Heatherton, 2011; Miller \& Cohen, 2001; Shenhav et al., 2013).

Adaptive control thus requires an individual to monitor their current state and the value of potential future outcomes that might be attained with available control. Such monitoring is intuitively important in sports and exercise: For athletic success, it is crucial to perform at (or close to) one's physiological limit without overextending oneself. Thus, athletes need to closely monitor their current state (e.g., pace) and flexibly adjust their behavior if this state is at odds (e.g., too slow) with the goal they aim to 
achieve (e.g., qualifying for the Olympics). As we have outlined above, these adjustments are made in order to invest self-regulatory control efficiently. In regard to control signal intensity, this means that the EVC is maximized when the intensity is as low as possible while still enabling goal attainment. For a marathon runner trying to qualify for the Olympic games, this implies that she will only invest the amount of mental effort needed to just achieve the qualifying time ${ }^{3}$. However, the emphasis on not wasting resources might sometimes lead to the specification of a control signal intensity that is too low. The marathon runner might for example follow a conservative pacing strategy (e.g., negative splittimes) but if she is unable to make up for lost time later in the race, she might eventually miss the qualification time. Thus, selecting an optimal pacing strategy ${ }^{4}$ is crucial to athletic success (Abbiss \& Laursen, 2008).

Research shows that the dACC monitors various indicators of state information (e.g., information that is relevant for control signal identity and intensity specification) in a fashion that is likely to subserve the computation of the EVC (Shenhav et al., 2013, 2016). The plethora of different bits of information that might be monitored during exercise is provided by various brain areas (Fig. 1A): Research indicates that interoceptive information (e.g., heavy breathing, locomotor fatigue) is processed by the insula (e.g., Gehrlach et al., 2019; Livneh et al., 2020), rewards (e.g., joy of running fast, achieving the qualification) are encoded by the ventromedial PFC (e.g., Gläscher, Hampton, \& O'Doherty, 2009; Strait, Blanchard, \& Hayden, 2014), and the amygdala may signal negative affective states such as fear of failure and exercise-induced pain (e.g., Neugebauer, Li, Bird, \& Han, 2004). The dACC monitors signals from these and other structures as information for computing the EVC. The monitored information then needs to be integrated to specify a control signal that maximizes EVC. Research indicates that the specification and, if required, adjustment of the control signal is performed by the dACC (e.g., Cavanagh \& Frank, 2014; Phillips, Johnston, \& Everling, 2011; Shackman et al., 2011; Ullsperger, Danielmeier, \& Jocham, 2014).

The EVC-maximizing control signal is then relayed to relevant downstream regions for execution. For many forms of self-regulatory control (e.g., controlling the impulse to get into a shoving match with an opponent after a foul; pulling oneself together to go out to train in the pouring rain), the region that appears to be most critical for this execution is IPFC (Miller \& Cohen, 2001). The dACC and IPFC share strong reciprocal connections (Heilbronner \& Hayden, 2016), and tend to co-activate in most controldemanding tasks (Duncan, 2010; Niendam et al., 2012). The strength of this dACC-IPFC co-activation has been shown to be predictive of good self-regulatory control, for instance improved performance on a rotation-letter task (Kondo, Osaka, \& Osaka, 2004). Of particular relevance to our central proposition in this chapter, namely that self-regulatory control is important for controlling sports performance, IPFC is also well-connected to structures in the motor system, including the premotor cortex, which is in turn extensively connected to areas of relevance for direct motor output, like the primary motor cortex and the basal ganglia (Miller \& Cohen, 2001). The connections between PFC and the basal ganglia are of interest in the domain of sports because the basal ganglia are believed to play a key role in generating central fatigue. Physical performance depends strongly on the capacity to tolerate fatigue, which may depend on top-down regulation of striatum by prefrontal cortical structures (Chaudhuri \& Behan, 2000).

\footnotetext{
${ }^{3}$ Clearly, this example only applies to a scenario where the runners' only goal is to qualify and not to achieve a personal best or win the race.

${ }^{4}$ Interestingly, research on pacing implies a process with striking similarity to EVC theory, when it comes to how athletes pace themselves during competition: "intensity is regulated within the brain based on a complex algorithm involving peripheral sensory feedback and the anticipated workload remaining" (Abbiss \& Laursen, 2008, p.239).
} 


\section{Cortical activity during self-regulated sports performance}

The bulk of the neuroscientific evidence that we have presented above stems from animal studies or human imaging studies that were performed under conditions that do not mirror real world situations. Although it has been proposed that sports might be the "brain's biggest challenge" (Walsh, 2014, p.859), research on the brain while a person is doing sport is still comparably scarce (Perrey \& Besson, 2018). However, this is rapidly changing. Over the last 25 years, researchers have become increasingly capable of and interested in the investigation of the sporting brain (Figure 2a). Of particular interest for the present chapter is the drastic uptick in research on the brain during sports. To illustrate this, we conducted a web of science search that combined the topics "sports" and "brain" and that also required the word "during" in the title of published articles (Figure $2 b$ ). This search returned only 8 hits during the twenty-year time span from 1995 and 2004. In the following 15 years, another 171 papers have been published and in 2019 alone, 26 papers fulfilled these search criteria. Thus, while this literature search is by no means comprehensive, it seems safe to say that research on the sporting brain is garnering momentum.

One likely reason for this momentum is the introduction of more portable and more robust technologies for measuring cortical processes during sports. Particularly functional near-infrared spectroscopy (fNIRS) and, to a lesser extent, electroencephalography (EEG) have been increasingly used in the sports context in recent years (Perrey \& Besson, 2018). While most readers are likely familiar with the basic operating principles of EEG, fNIRS is a comparatively recent neuroimaging technology whose specific advantages and disadvantages are less well known. Thus, prior to summarizing the literature on self-regulated sports performance, we will briefly describe the operating principles of fNIRS.

\section{Measuring the sporting brain: fNIRS}

Neuronal activity consumes energy and local changes in neuronal activity cause local increases in oxygenated blood. In the blood, oxygen is transported by the chromophore hemoglobin, which occurs in an oxygenated $(\mathrm{HbO})$ and a deoxygenated $(\mathrm{HbR})$ variant. Like functional magnetic resonance imaging, fNIRS tracks the resultant change of balance between $\mathrm{HbO}$ and $\mathrm{HbR}$ as a marker for neuronal activity. fNIRS uses NIR light to measure changes in $\mathrm{HbO}$ and $\mathrm{HbR}$ non-invasively in the cerebral cortex (Scholkmann et al., 2014). To do so, NIR light emitting senders and NIR light sensitive detectors are placed on the participants' scalp (see Figure 3a), according to a predefined setup (see Figure 3b) that is designed to capture regions of interest (see Figure 3c). The NIR light spectrum ranges from 700nm to $1400 \mathrm{~nm}$ and within this spectrum, $\mathrm{HbO}$ absorbs substantially more light at ranges above $830 \mathrm{~nm}$ and $\mathrm{HbR}$ absorbs more light at 760nm (Ekkekakis, 2009). Capitalizing on this differentiation in absorption
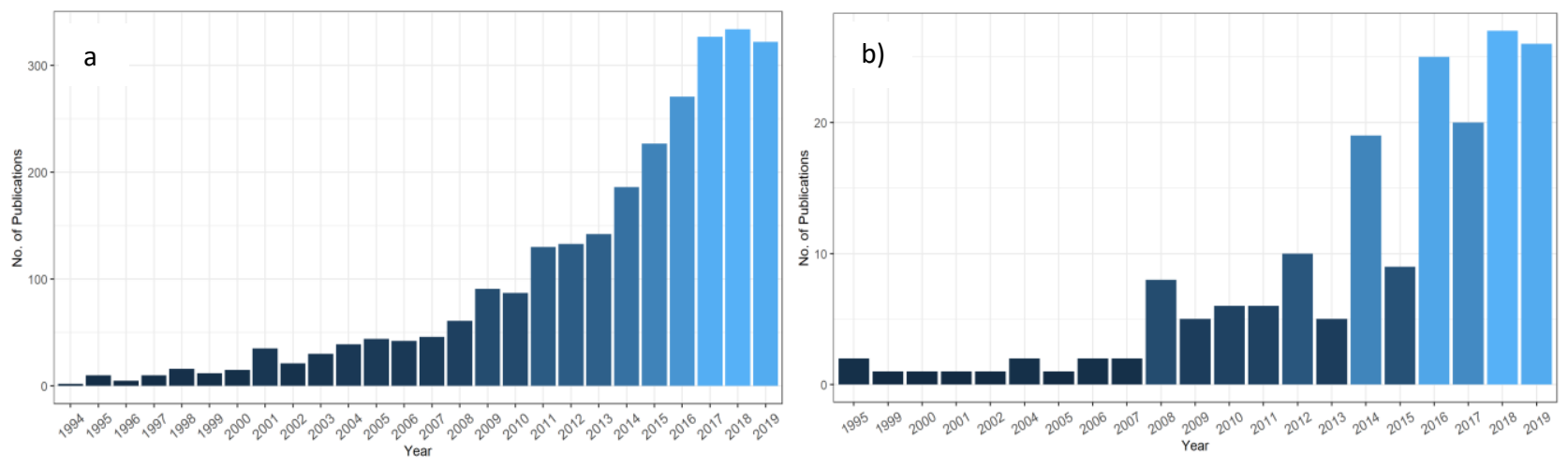

Figure 2. Web of Science Search (per January 2020) on the publication trends for neuroscientific research in regard to sports. Panel a) illustrates the broad increase in research into the sporting brain (search terms: sports AND brain). Panel b) only includes papers that additionally have the term "during" in their title, to illustrate the relative scarcity and the increase in research on brain activity while people do sports. 
spectra, fNIRS senders emit light in two wavelengths (e.g., 760nm and $850 \mathrm{~nm}$ ) and detectors nearby ${ }^{5}$ track how much of the emitted NIR light leaves the scalp. Relative changes in the detected light are then analyzed as indicators for $\mathrm{HbO} / \mathrm{HbR}$ fluctuations, which serve as a proxy for change in cortical activity (Ferrari, Mottola, \& Quaresima, 2004). For assessing cortical activity during sports, fNIRS has been regarded as the best suited technology that is currently available (Ekkekakis, 2009; Herold, Wiegel, Scholkmann, \& Müller, 2018). Most important for sports settings, fNIRS is comparatively robust to motion artifacts, has acceptable temporal resolution and - due to its portability - can be used in settings with high external validity (Ekkekakis, 2009; Strangman, Culver, Thompson, \& Boas, 2002). fNIRS has even been used to measure activity in the motor cortex in freely moving participants (Piper et al., 2014). Specifically, these authors were interested in whether hemodynamic changes that originate from hand movement could be captured while participants where sitting on a bike in decreasingly less controlled conditions: participants either sat on a stationary bike without pedalling, were pedalling on a stationary bike, or were freely riding their bike outside. Although an increase in external validity was acompanied by an increase in motion artifacts, the hemodynamic response that was triggered by the hand movement in the contralateral motor cortex could still be recovered (Piper, et al., 2014). In addition, compared to technologies like fMRI, fNIRS is cheap to acquire and produces little running costs (Wolff, 2017). Finally, compared to fMRI and EEG, fNIRS measurements tend to be perceived as less invasive and aversive by participants (Cutini \& Brigadoi, 2014). Constraining its applicability, fNIRS can only be used to reliably measure oxygenation changes in superficial cortical areas, whereas limited depth penetration prevents the measurement of deep brain areas (Ferrari \& Quaresima, 2012). With respect to the key cortical structures involved in self-regulatory control, fNIRS is therefore well-suited for monitoring activity in the IPFC but not in the dACC. Thus, most of the literature we review below has focused on IPFC, whereas research on dACC is scarce. Further, although the spatial resolution of current fNIRS devices is $\leq 1 \mathrm{~cm}$ (Ferrari \& Quaresima, 2012), fNIRS is less accurate than the spatial resolution that can be achieved with fMRI. Thus, for research that requires very precise localization or is concerned with subcortical areas, fNIRS is less well suited. However, to assess group-level effects (e.g., comparing groups of trained and non-trained participants), fNIRS has proven to be a reliable neuroimaging technique (Scholkmann et al., 2014) and has accordingly gained in popularity in the domain of sports in recent years (for a more comprehensive introduction of fNIRS to research in sports, please see Ekkekakis, 2009; Perrey \& Besson, 2018).
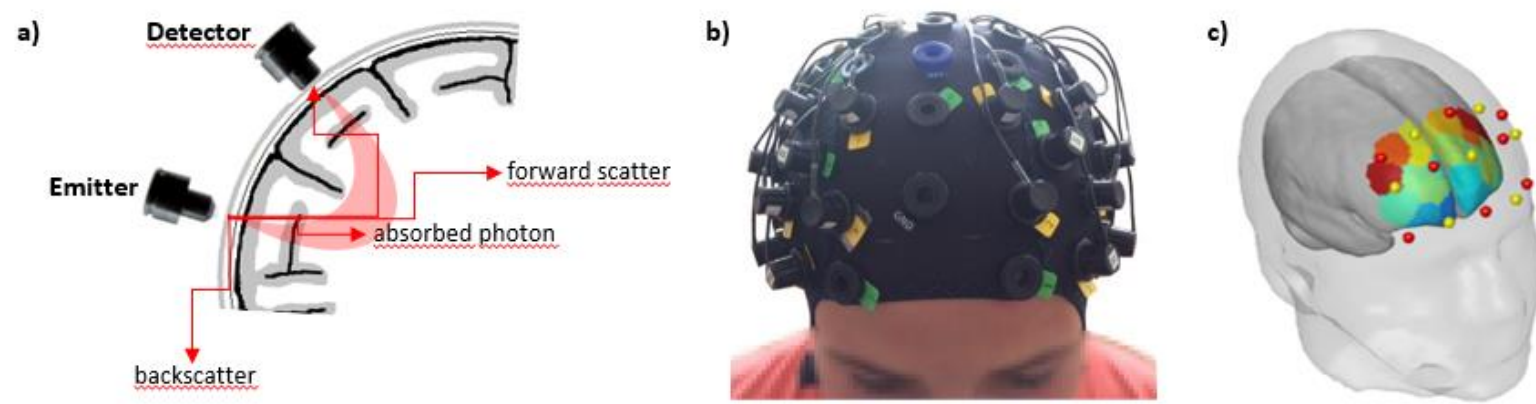

Figure 3. fNIRS Setup: a) Schematic illustration of NIR light pathway between emitter and detector, b) illustration of fNIRS montage designed to capture oxygenation changes in the dorsolateral prefrontal cortex and c) illustration of the sensitivity profile for capturing specific regions based on the montage designed to capture changes in the dorsolateral prefrontal cortex.

\footnotetext{
${ }^{5}$ Research suggests that sender-detector separations of ca. $3 \mathrm{~cm}$ optimize signal-to-noise ratio (Boas, Elwell, Ferrari, \& Taga, 2014; Ekkekakis, 2009)
} 


\section{Brain activity during self-regulated sports performance}

Only recently have researchers started to explicitly conceptualize sports performance as a selfregulatory challenge (Marcora, 2008; McCormick, Meijen, Anstiss, \& Jones, 2018; Pageaux, 2014; Wolff, Bieleke et al., 2018). Consequently, many early studies on the brain's role in exercising have focused on explaining exercise-induced activation changes in the brain from a physiological point of view (e.g., Rooks, Thom, McCully, \& Dishman, 2010; Secher, Seifert, \& Van Lieshout, 2008). For example, a systematic review of 25 fNIRS studies that were published between 1999 and 2009 concluded that with increasing exercise intensity, activation in the IPFC increased until it dropped at very high intensities (Rooks et al., 2010). One interpretation of this pattern suggested that this reflects an automatic physiological response that is initiated to prevent harmful threats to bodily homeostasis when exercise intensity is dangerously high ${ }^{6}$ (Noakes, Peltonen, \& Rusko, 2001; Rooks et al., 2010). However, rather than reflecting an obligatory response to a physiological limitation, these same findings could reflect the endpoint of a decision process, which weighs the value of applying further effort against the cost of this effort. Specifically, these changes in IPFC activity could be conceptualized in terms of variability in self-regulatory control: During an incremental exercise protocol (for example, riding on a cycling ergometer until exhaustion), the self-regulatory demands rise steadily because the task becomes increasingly more challenging and participants have to fight the impulse to quit. From an EVC perspective, to apply the self-regulatory control that is required to continue in spite of these aversive sensations, the control signal intensity needs to be constantly upregulated by the dACC and more regulative control needs to be applied by the IPFC (Fig. 1B). Thus, if one understands an incremental exercise task as a self-regulatory challenge (Wolff, Bieleke et al., 2018), an increase in IPFC oxygenation is expected over time. This assumption is supported by findings of recent fNIRS studies. For example, in one study, IPFC oxygenation during a 30-minute cycling task increased as a function of duration and intensity in a sample of regularly exercising athletes (Giles et al., 2014), probably accompanying increasing levels of self-regulatory control. Similarly, when participants had to hold $50 \%$ of their maximum voluntary handgrip force, this self-control demanding performance was associated with higher IPFC oxygenation, compared to a condition when only $30 \%$ of maximum force was required (Zengzhi Guo, Ting Ma, \& Fei Chen, 2019). However, at a certain exercise intensity, the cost of exerting the level of self-regulatory control that would be required to continue with the task (e.g., controlling the impulse to stop) will exceed the expected payoff from the task (e.g., from receiving course credit for participating in an experiment). From an EVC perspective, this shift in EVC should motivate the person to reduce the intensity of self-regulatory control they are applying (Frömer, Lin, Dean Wolf, Inzlicht, \& Shenhav, 2020), leading to a drop in PFC oxygenation and subsequent task termination. Indeed, an EEG study where cyclists completed an incremental cycling test showed that after an initial rise in PFC activation, a significant drop was observed after the respiratory compensation point (Robertson \& Marino, 2015). A similar result could be observed in an fNIRS study with trained cyclists: in a progressive maximal cycling exercise to exhaustion, IPFC oxygenation increased in the first part of the cycling task but decreased significantly prior to task termination (Rupp \& Perrey, 2008). Interestingly, a drop in IPFC activation does not lead to immediate task termination but participants continue for some more time ${ }^{7}$ (e.g., Wolff, Bieleke et al., 2018). One possible explanation for this finding is that exercisers specify control signal intensities that have a built-in anticipatory buffer to be prepared in case exercise gets more demanding. The quick drop in IPFC oxygenation that has been observed prior to task termination might then reflect the dropping of EVC until the specified control intensity does not suffice to continue with the task. This is in line with research showing that a certain

\footnotetext{
${ }^{6}$ Indeed, research shows that task termination occurs well before physiological resources are fully depleted or bodily homeostasis is threatened (Marcora \& Staiano, 2010; Morales-Alamo et al., 2015).

${ }^{7}$ Systematic research on how long participants continue after this drop is currently lacking and represents an exciting future research question.
} 
activity level in IPFC is required to engage in an effortful task (Hosking et al., 2016). In addition, this pattern might also reflect some form of task inertia: changing a self-regulatory control signal produces costs in itself and these reconfiguration costs can deter people from switching to another activity (Monsell, 2003; Musslick, et al., 2018).

\section{Trained athletes process exercise-induced demands more efficiently}

Some studies have compared exercise-induced cortical activation changes in trained athletes and untrained participants (e.g., Ludyga, Gronwald, \& Hottenrott, 2016; Rooks et al., 2010; Seidel, Carius, Roediger, Rumpf, \& Ragert, 2019). Interestingly, in the systematic review by Rooks et al. (2010), the drop in PFC oxygenation prior to task termination has been observed in untrained participants but not in trained athletes. Trained athletes have extensive experience in adjusting their mental and physical efforts as a function of the challenge at hand, by interpreting sensations from their body. It is therefore conceivable that trained athletes are better able to anticipate expected control costs and the likelihood of potential future rewards, resulting in better-calibrated estimates of EVC. Behavioral data in support of this hypothesis comes from an analysis of the pacing profiles of 190,228 finishers of the New York Marathon. Here, the variability in $5 \mathrm{~km}$ split times was substantially lower for top runners compared to less successful runners (Santos-Lozano, Collado, Foster, Lucia, \& Garatachea, 2014).

Further, the neural efficiency hypothesis suggests that experts are more efficient in using their cortical resources for performing mental operations (Dunst et al., 2014). For example, more intelligent individuals perform cognitive tasks with lower brain activation, indicating the investment of less mental effort (Dunst et al., 2014). Applying this finding to the sports setting, trained athletes exhibit a less pronounced increase in PFC oxygenation during incremental exercise than untrained participants (Rooks et al., 2010). This is also in line with research showing that participants who score highly on a self-report measure of trait self-regulatory control display a less steep increase in IPFC oxygenation over the course of a fatiguing static muscular endurance task (Wolff, Schüler et al., 2019). This might point towards a more efficient use of processing resources. Interestingly, when task demands were standardized with respect to participants' individual capability (e.g., $60 \%$ of one's maximum power output on a cycling task), these expert-novice differences in brain oxygenation have not been observed (Dunst et al., 2014; Seidel et al., 2019). Adding to evidence from fNIRS studies, a recent study used EEG to measure the $\alpha$-wave/ $\beta$-wave ratio as a marker for neural efficiency ${ }^{8}$, and compared well-trained to less well-trained cyclists (Ludyga et al., 2016). Higher $\alpha / \beta$ ratios were observed over frontal sites in well-trained cyclists, supporting the neural efficiency hypotheses. Although they do not explicitly refer to self-regulatory control, the authors suggest that superior athletes might be better at inhibiting taskirrelevant cognitive processes. Going back to the proposition that the control demands of a task vary as a function of its automaticity and of its reliance on shared local processing pathways, these findings fit well into the theorizing on self-regulatory control we present here. Compared to non-athletes, trained athletes have been repeatedly exposed to the multitude of self-regulatory challenges one faces during exercise (McCormick, Meijen, \& Marcora, 2016) and this experience likely leads to a greater automatization in the processing of these regulatory demands ${ }^{9}$. Thus, it is conceivable that trained

\footnotetext{
${ }^{8} \alpha$-waves are associated with mental inactivity and $\beta$-waves have been linked with cognitive information processing. Thus, if a demanding task is performed with a high $\alpha$-wave/ $\beta$-wave ratio, this can be interpreted as an indicator for energy efficient cortical functioning (Ludyga et al., 2016).

${ }^{9}$ It has to be noted that, while some research supports the notion that specific physical or cognitive trainings generalize beyond the specific functions they presumably address (e.g., Jaeggi, Buschkuehl, Jonides, \& Perrig, 2008; Sherrington, Tiedemann, Fairhall, Close, \& Lord, 2011), there is also an accumulating body of research that indicates that such effects are task specific and do not generalize (e.g., Giboin, Gruber, \& Kramer, 2015; Giboin et al., 2019, Melby-Lervag \& Hulme, 2013).
} 
athletes process self-regulatory demands during sports more efficiently and specify more realistic EVC's that are more accurately matched to the current task demands.

\section{Psychological manipulations affect cortical changes during sports}

Recently, researchers have started to investigate the effect psychological manipulations have on effort-related sensations and on cortical activity while participants perform sports. For example, one way to reduce the self-regulatory costs of an action is to make that action more automatic (Bayer, Achtziger, Gollwitzer, \& Moskowitz, 2009; Gollwitzer, 1999; see also the chapter by Hagger and colleagues in this volume for an in-depth discussion of the topic). Accordingly, researchers have investigated the effects of self-regulatory strategies that aim to automatize behavior (Bieleke \& Wolff, 2017; Wolff, Bieleke et al., 2018). Interestingly, while such a self-regulatory intervention did not lead to improved performance in a static muscular endurance task, participants were able to perform the task with a less pronounced increase in IPFC activation, indicating that the task had been performed in a neuronally more efficient way (Wolff, Bieleke et al., 2018). Another study used the multi-action plan (MAP) model (Robazza, Bertollo, Filho, Hanin, \& Bortoli, 2016) to derive functional and dysfunctional pacing strategies and assess their effect on cycling performance and on EEG coherence (as a measure of functional connectivity; Di Fronso et al., 2018). When applying the dysfunctional strategy, participants were asked to focus their attention internally on feelings of muscle exertion. According to the MAP model, this internal focus on aversive sensations is detrimental to performance because it enhances perceived fatigue. Indeed, applying a dysfunctional strategy was associated with higher EEG coherence at high intensities, potentially indicating excessive attentional focus on muscle exertion (Di Fronso et al., 2018). Interpreting this finding from the perspective of self-regulatory control, adopting a dysfunctional pacing strategy might have resulted in inefficient or excessive allocation of selfregulatory control. In line with this argument, low coherence was observed when participants adopted a functional pacing strategy. Other researchers induced heat stress to alter the costs of exercise. Here, changes in frontal areas of the brain were observed, again likely reflecting changes in the "capacity to sustain mental readiness and arousal" (Périard, Pauw, Zanow, \& Racinais, 2018, p.1).

We are aware of only one study that has investigated the influence of experimentally manipulating the value of self-regulatory control on IPFC oxygenation and physical performance: In this fNIRS study, participants performed an isometric knee extension task until voluntary task termination on two occasions (Giboin, Gruber, Schüler, \& Wolff, 2019). In the control group, participants received the same reward per minute in both sessions. Participants in the experimental group received $50 \%$ less reward per minute in Session 2 compared to Session 1, but were also compensated with an upfront payment that was calibrated so they would earn exactly the same total reward in the second session if they performed the task for the same duration as in the first session. Previous research has shown that this form of income-compensated wage decrease (ICWD) reduces the willingness to invest self-regulatory control during that second session (Kool \& Botvinick, 2014). Consistent with this finding, IPFC oxygenation was lower in the ICWD group in the second session. However, counter to expectations, this decrease was not associated with poorer performance, as would be expected if this group was exerting less mental effort. Instead, the ICWD group in fact persisted longer in the knee extension task. One potential explanation for this is that the unexpected performance improvement we observed was achieved by a more efficient execution of the task. Indeed, post-hoc analyses revealed that participants in the ICWD group deviated less from the target force that had to be produced, thereby executing the task with less force than the control group. There were no group differences in perceived effort and in a host of objective markers of physiological exertion (maximal voluntary contraction, voluntary activation, potentiated twitch at rest, and electromyographic activity). Collectively, these findings suggest that, under certain conditions, increasing the value of self-regulatory control might lead to an overexertion of physiological resources and thereby produce more costs and hamper performance. 
Interestingly, this aligns well with recent work showing that predictions people make from previous reward learning can cause them to overexert self-regulatory control (Bustamante et al., 2020).

Another branch of research has investigated the effects of providing inaccurate information regarding the duration of an endurance task on IPFC oxygenation and performance. For example, in one study, participants either knew or did not know how long a cycling task was going to last (Wingfield et al., 2018). Withholding information on task duration can be understood as a manipulation that complicates the initial computation of the EVC and, subsequently, the adequate updating of EVC based on ones' current state. In line with this reasoning, participants who knew the distance invested more effort at the end of the task which was accompanied by an increase in IPFC oxygenation. In contrast, participants without this information adopted a more conservative pacing strategy and performed worse (Wingfield et al., 2018). A similar pattern was observed in a cycling study where one group of cyclists was told to cycle for ten minutes, while a second group was told to cycle for sixty minutes (Radel, Brisswalter, \& Perrey, 2017). However, in the second group, the task was terminated after ten minutes as well. Participants who expected to expend their effort over a longer period of time displayed lower IPFC activation than participants who expected to cycle for only ten minutes.

\section{Beyond endurance performance}

The bulk of the neuroscientific literature we reviewed here concerned endurance performance. This has at least two reasons: Firstly, the self-regulatory challenges of endurance performance are ideal to study self-regulatory control, given that the regulation of effort is at the heart of endurance sports and that perceived exertion is a fundamental sensation that characterizes the application of self-regulatory control (Wolff \& Martarelli, 2020). Secondly, endurance performance - especially time trial cycling or static muscular endurance - allows for a comparatively controlled and stable measurement of cortical processes because the upper body is relatively stable and athletes usually do not make abrupt movements.

However, researchers have also investigated other types of sports, and their findings are compatible with those obtained in the domain of endurance performance. For example, a recent study found that a more complex juggling task (e.g., 5-ball cascade vs. 2-ball cascade) was accompanied by more oxygenation over motor areas, whereas a higher level of juggling expertise tended to be associated with less oxygenation (Carius et al., 2016). However, as activity was only monitored over motor areas it remains unclear whether the juggling task also elicited an increase in IPFC oxygenation. Considering the projections from the IPFC to premotor areas (Miller \& Cohen, 2001) and the self-regulatory demands imposed by the task (i.e., attentional control for tracking ball trajectories), this would be likely. Another recent study investigated changes in oxygenation in the IPFC during a series of sprint start sequences (Wolff, Thürmer, Stadler, \& Schüler, 2019). Participants were instructed to either produce a fast sprint start on the Go-signal or not to start on the Go-signal (no-start condition). Thus, in the condition where participants actually had to start, they had to balance the impulse to start too fast with the requirement of starting as fast as possible on the Go-signal. In the no-start condition, by contrast, participants only had to restrain the impulse of accidentally starting upon the Go-Signal. From an EVC perspective, both tasks required a control signal to be specified to prevent a false start (i.e., response inhibition). However, when actual starts were required, an additional control signal needed to be specified to initiate a fast start as soon as the Go-signal occurred (i.e., action initiation). In line with this reasoning, an increase in PFC oxygenation in the period between the Set-signal and the Gosignal was observed in both conditions. However, this increase was even more pronounced in the condition where participants actually had to produce a start. 


\section{Conclusion}

Taken together, the literature reviewed in this chapter demonstrates that research on the neuroscience of self-regulatory control in sports is still in its infancy but has started to gather considerable momentum (see Figure 2). Performance in sports is increasingly understood as a task with inherent self-regulatory demands that athletes must cope with effectively. This perspective opens the field for innovative insights from research addressing the "whys" and "whens" of successful selfregulatory control. In particular, theories that conceive of self-regulatory control as the output of a reward-based decision offer a comprehensive computational framework that allows specific predictions regarding behavior and its neurophysiological mechanisms. As we have shown, components of one such framework, the EVC theory, can be plausibly related to various aspects of performance in sports, ranging from the initial willingness to invest effort to the decision to terminate a task. Fortunately, state-of-the-art brain imaging technology nowadays permits several intriguing ways of capturing and manipulating neurophysiological processes during exercise, providing glimpses into what has been referred to as the "sporting brain" (Walsh, 2014, R859). That said, we feel it is important to call for more neuroscientific research on self-regulated sports performance because key questions have not yet been addressed comprehensively. It will be important to test the dACC's proposed role during sports performance, to analyze the effect of directly manipulating the value of self-regulatory control, to investigate the potential neurocomputational overlap between physical and mental effort (Ritz, Frömer, \& Shenhav, 2020), and to get a better understanding of the differences between elite and recreational athletes in the neuronal processing of the self-regulatory demands in sports. We believe these are exciting questions and with this chapter we hope to encourage further research on self-regulatory control in sports. 


\section{References}

Abbiss, C. R., \& Laursen, P. B. (2008). Describing and understanding pacing strategies during athletic competition. Sports Medicine, 38, 239-252. https://doi.org/10.2165/00007256-200838030-00004

Alé La Merckx (2018, June 7). Eddy Merckx: Mind traits of a legend. Retrieved March 24, 2020, from https://www.alelamerckx.com/en/news/eddy-merckx-i-tratti-psicologici-di-una-leggenda

Al-Yahya, E., Dawes, H., Smith, L., Dennis, A., Howells, K., \& Cockburn, J. (2011). Cognitive motor interference while walking: A systematic review and meta-analysis. Neuroscience and Biobehavioral Reviews, 35, 715-728. https://doi.org/10.1016/j.neubiorev.2010.08.008

Andersen, J. (2020, March 30). The state of running 2019. RunRepeat. Retrieved March 24, 2020, from https://runrepeat.com/state-of-running

Badre, D. (2008). Cognitive control, hierarchy, and the rostro-caudal organization of the frontal lobes. Trends in Cognitive Cciences, 12(5), 193-200. https://doi.org/10.1016/j.tics.2008.02.004

Baumeister, R. F., Bratslavsky, E., Muraven, M., \& Tice, D. M. (1998). Ego depletion: Is the active self a limited resource? Journal of Personality and Social Psychology, 74, 1252-1265. https://doi.org/10.1037/0022-3514.74.5.1252

Bayer, U. C., Achtziger, A., Gollwitzer, P. M., \& Moskowitz, G. B. (2009). Responding to subliminal cues: do if-then plans facilitate action preparation and initiation without conscious intent? Social Cognition, 27, 183-201. https://doi.org/10.1521/soco.2009.27.2.183

Beedie, C. J., \& Lane, A. M. (2012). The role of glucose in self-control: Another look at the evidence and an alternative conceptualization. Personality and Social Psychology Review, 16, 143-153. https://doi.org/10.1177/1088868311419817

Berkman, E. T., Hutcherson, C. A., Livingston, J. L., Kahn, L. E., \& Inzlicht, M. (2017). Self-control as value-based choice. Current Directions in Psychological Science, 26, 422-428. https://doi.org/10.1177/0963721417704394

Bieleke, M., \& Wolff, W. (2017). That escalated quickly-Planning to ignore RPE can backfire. Frontiers in Physiology, 8, 736. https://doi.org/10.3389/fphys.2017.00736

Blain, B., Schmit, C., Aubry, A., Hausswirth, C., Le Meur, Y., \& Pessiglione, M. (2019). Neurocomputational impact of physical training overload on economic decision-making. Current Biology, 29, 3289-3297.e4. https://doi.org/10.1016/i.cub.2019.08.054

Boas, D. A., Elwell, C. E., Ferrari, M., \& Taga, G. (2014). Twenty years of functional near-infrared spectroscopy: Introduction for the special issue. Neurolmage, 85 Pt 1, 1-5. https://doi.org/10.1016/j.neuroimage.2013.11.033

Bustamante, L. A., Lieder, F., Musslick, S., Shenhav, A., \& Cohen, J. D. (2020). Learning to overexert cognitive control in a Stroop task. https://doi.org/10.31234/osf.io/3ryni

Carius, D., Andrä, C., Clauß, M., Ragert, P., Bunk, M., \& Mehnert, J. (2016). Hemodynamic response alteration as a function of task complexity and expertise-An fNIRS study in jugglers. Frontiers in Human Neuroscience, 10, 126. https://doi.org/10.3389/fnhum.2016.00126

Carter, E. C., \& McCullough, M. E. (2014). Publication bias and the limited strength model of selfcontrol: Has the evidence for ego depletion been overestimated? Frontiers in Psychology, 5, 823. https://doi.org/10.3389/fpsyg.2014.00823 
Cavanagh, J. F., \& Frank, M. J. (2014). Frontal theta as a mechanism for cognitive control. Trends in Cognitive Sciences, 18, 414-421. https://doi.org/10.1016/j.tics.2014.04.012

Cavanagh, J. F., \& Shackman, A. J. (2015). Frontal midline theta reflects anxiety and cognitive control: Meta-analytic evidence. Journal of Physiology, Paris, 109, 3-15. https://doi.org/10.1016/i.jphysparis.2014.04.003

Chaudhuri, A., \& Behan, P. O. (2000). Fatigue and basal ganglia. Journal of the Neurological Sciences, 179, 34-42. https://doi.org/10.1016/S0022-510X(00)00411-1

Cohen, J., Dunbar, K., \& Mcclelland, J. (1990). On the control of automatic processes: A parallel distributed processing account of the Stroop effect. Psychological Review 97, 332 - 361. https://doi.org/10.1037/0033-295X.97.3.332

Critchfield, T. S., \& Kollins, S. H. (2001). Temporal discounting: Basic research and the analysis of socially important behavior. Journal of Applied Behavior Analysis, 34, 101-122. https://doi.org/10.1901/jaba.2001.34-101

Cutini, S., \& Brigadoi, S. (2014). Unleashing the future potential of functional near-infrared spectroscopy in brain sciences. Journal of Neuroscience Methods, 232, 152-156. https://doi.org/10.1016/i.jneumeth.2014.05.024

Darling, K. A., \& Helton, W. S. (2014). Dual-task interference between climbing and a simulated communication task. Experimental Brain Research, 232, 1367-1377. https://doi.org/10.1007/s00221-014-3855-7

De Ridder, D. T. D., Lensvelt-Mulders, G., Finkenauer, C., Stok, F. M., \& Baumeister, R. F. (2012). Taking stock of self-control: A meta-analysis of how trait self-control relates to a wide range of behaviors. Personality and Social Psychology Review, 16, 76-99. https://doi.org/10.1177/1088868311418749

Di Fronso, S., Tamburro, G., Robazza, C., Bortoli, L., Comani, S., \& Bertollo, M. (2018). Focusing attention on muscle exertion increases EEG coherence in an endurance cycling task. Frontiers in Psychology, 9, 1249. https://doi.org/10.3389/fpsyg.2018.01249

Duncan, J. (2010). The multiple-demand (MD) system of the primate brain: Mental programs for intelligent behaviour. Trends in Cognitive Sciences, 14, 172-179. https://doi.org/ 10.1016/j.tics.2010.01.004

Dunst, B., Benedek, M., Jauk, E., Bergner, S., Koschutnig, K., Sommer, M., ... Neubauer, A. C. (2014). Neural efficiency as a function of task demands. Intelligence, 42, 22-30. https://doi.org/10.1016/i.intell.2013.09.005

Eisenberger, R. (1992). Learned industriousness. Psychological review, 99, 248. https://doi.org/10.1037/0033-295X.99.2.248

Ekkekakis, P. (2009). Illuminating the black box: Investigating prefrontal cortical hemodynamics during exercise with near-infrared spectroscopy. Journal of Sport and Exercise Psychology, 31, 505-553. https://doi.org/10.1123/jsep.31.4.505

Ekkekakis, P., Parfitt, G., \& Petruzzello, S. J. (2011). The pleasure and displeasure people feel when they exercise at different intensities. Sports Medicine, 41, 641-671. 10.2165/11590680$\underline{000000000-00000}$ 
Englert, C. (2016). The strength model of self-control in sport and exercise psychology. Frontiers in Psychology, 7, 179. https://doi.org/10.3389/fpsyg.2016.00314

Englert, C., Persaud, B. N., Oudejans, R. R. D., \& Bertrams, A. (2015). The influence of ego depletion on sprint start performance in athletes without track and field experience. Frontiers in Psychology, 6, 1207. https://doi.org/10.3389/fpsyg.2015.01207

Feng, S. F., Schwemmer, M., Gershman, S. J., \& Cohen, J. D. (2014). Multitasking versus multiplexing: Toward a normative account of limitations in the simultaneous execution of control-demanding behaviors. Cognitive, Affective, \& Behavioral Neuroscience, 14, 129-146.

https://doi.org/10.3758/s13415-013-0236-9

Ferrari, M., Mottola, L., \& Quaresima, V. (2004). Principles, techniques, and limitations of near infrared spectroscopy. Canadian Journal of Applied Physiology, 29, 463-487. https://doi.org/10.1139/h04-031

Ferrari, M., \& Quaresima, V. (2012). A brief review on the history of human functional near-infrared spectroscopy (fNIRS) development and fields of application. Neurolmage, 63, 921-935. https://doi.org/10.1016/i.neuroimage.2012.03.049

Finn, A., (2018, April 2). When 26.2 miles just isn't enough - the phenomenal rise of the ultramarathon. The Guardian. Retrieved March 24, 2020, from https://www.theguardian.com/lifeandstyle/2018/apr/02/ultrarunner-ultramarathon-racing-100miles

Frederick, S., Loewenstein, G., O'donoghue, T. (2002). Time discounting and time preference: A critical review. Journal of Economic Literature XL, 351 - 401.

https://doi.org/10.1257/002205102320161311

Frömer, R., Lin, H., Dean Wolf, C. K., Inzlicht, M., Shenhav, A. (2020, May 20). When effort matters: Expectations of reward and efficacy guide cognitive control allocation. https://doi.org/10.1101/2020.05.14.095935.2020.

Gehrlach, D. A., Dolensek, N., Klein, A. S., Chowdhury, R. R., Matthys, A., Junghänel, M., ... \& Conzelmann, K. K. (2019). Aversive state processing in the posterior insular cortex. Nature Neuroscience, 22, 1424-1437. https://doi.org/10.1038/s41593-019-0469-1

Gendolla, G. H. E., \& Richter, M. (2010). Effort mobilization when the self is involved: Some lessons from the cardiovascular system. Review of General Psychology, 14, 212-226. https://doi.org/10.1037/a0019742

Giboin, L. S., Gruber, M., \& Kramer, A. (2015). Task-specificity of balance training. Human Movement Science, 44, 22-31. https://doi.org/10.1016/j.humov.2015.08.012

Giboin, L.-S., Gruber, M., Schüler, J., \& Wolff, W. (2019). Investigating performance in a strenuous physical task from the perspective of self-control. Brain Sciences, 9. https://doi.org/10.3390/brainsci9110317

Giboin, L. S., Loewe, K., Hassa, T., Kramer, A., Dettmers, C., Spiteri, S., ... \& Schoenfeld, M. A. (2019). Cortical, subcortical and spinal neural correlates of slackline training-induced balance performance improvements. Neurolmage, 202, 116061.

https://doi.org/10.1016/i.neuroimage.2019.116061 
Giboin, L. S., \& Wolff, W. (2019). The effect of ego depletion or mental fatigue on subsequent physical endurance performance: A meta-analysis. Performance Enhancement \& Health, 7, 100150. https://doi.org/10.1016/j.peh.2019.100150

Giles, G. E., Brunyé, T. T., Eddy, M. D., Mahoney, C. R., Gagnon, S. A., Taylor, H. A., \& Kanarek, R. B. (2014). Acute exercise increases oxygenated and deoxygenated hemoglobin in the prefrontal cortex. Neuroreport, 25, 1320-1325. https://doi.org/10.1097/WNR.0000000000000266

Gläscher, J., Hampton, A. N., \& O’Doherty, J. P. (2009). Determining a role for ventromedial prefrontal cortex in encoding action-based value signals during reward-related decision making. Cerebral Cortex, 19, 483-495. https://doi.org/10.1093/cercor/bhn098

Gollwitzer, P. M. (1999). Implementation intentions: Strong effects of simple plans. American Psychologist, 54, 493. https://doi.org/10.1037/0003-066X.54.7.493

Hagger, M. S., \& Chatzisarantis, N. L. D. (2016). A multilab preregistered replication of the egodepletion effect. Perspectives on Psychological Science, 11, 546-573. https://doi.org/10.1177/1745691616652873

Heatherton, T. F. (2011). Neuroscience of self and self-regulation. Annual Review of Psychology, 62, 363-390. https://doi.org/10.1146/annurev.psych.121208.131616

Heilbronner, S. R., \& Hayden, B. Y. (2016). Dorsal anterior cingulate cortex: A bottom-up view. Annual Review of Neuroscience, 39, 149-170. https://doi.org/10.1146/annurev-neuro-070815-013952

Herold, F., Wiegel, P., Scholkmann, F., Müller, N. G. (2018). Applications of functional near-infrared spectroscopy (fNIRS) neuroimaging in exercise-cognition science: a systematic, methodologyfocused review. Journal of Clinical Medicine, 7(12), 466. https://doi.org/10.3390/icm7120466

Holgado, D., Troya, E., Perales, J. C., Vadillo, M. A., \& Sanabria, D. (2019). Does mental fatigue impair physical performance? A replication study. https://doi.org/10.31236/osf.io/tzn6d

Hosking, J. G., Cocker, P. J., \& Winstanley, C. A. (2016). Prefrontal cortical inactivations decrease willingness to expend cognitive effort on a rodent cost/benefit decision-making task. Cerebral Cortex, 26, 1529-1538. https://doi.org/10.1093/cercor/bhu321

Hull, C. L. (1943). Principles of Behavior (Vol. 422). New York: Appleton-century-crofts.

Inzlicht, M., Schmeichel, B. J., \& Macrae, C. N. (2014). Why self-control seems (but may not be) limited. Trends in Cognitive Sciences, 18, 127-133. https://doi.org/10.1016/j.tics.2013.12.009

Inzlicht, M., Shenhav, A., \& Olivola, C. Y. (2018). The effort paradox: Effort is both costly and valued. Trends in Cognitive Sciences, 22, 337-349. https://doi.org/10.1016/i.tics.2018.01.007

Jaeggi, S. M., Buschkuehl, M., Jonides, J., \& Perrig, W. J. (2008). Improving fluid intelligence with training on working memory. Proceedings of the National Academy of Sciences of the United States of America, 105, 6829-6833. https://doi.org/10.1073/pnas.0801268105.

Kerns, J. G. (2004). Anterior cingulate conflict monitoring and adjustments in control. Science, 303, 1023-1026. https://doi.org/10.1126/science.1089910

Keville, G. (2015, January 07). "The more difficult the victory, the greater the happiness in winning" 25 inspirational sports quotes. Independent. Retrieved March 24, 2020, from https://www.independent.ie/sport/other-sports/the-more-difficult-the-victory-the-greater-thehappiness-in-winning-25-inspirational-sports-quotes-30889900.html 
Kondo, H., Osaka, N., \& Osaka, M. (2004). Cooperation of the anterior cingulate cortex and dorsolateral prefrontal cortex for attention shifting. Neurolmage, 23, 670-679. https://doi.org/10.1016/j.neuroimage.2004.06.014

Kool, W., \& Botvinick, M. M. (2014). A labor/leisure tradeoff in cognitive control. Journal of Experimental Psychology. General, 143, 131-141. https://doi.org/10.1037/a0031048

Kool, W., \& Botvinick, M. (2018). Mental labour. Nature Human Behaviour, 2, 899-908. https://doi.org/10.1038/s41562-018-0401-9

Körding, K. P., Fukunaga, I., Howard, I. S., Ingram, J. N., \& Wolpert, D. M. (2004). A neuroeconomics approach to inferring utility functions in sensorimotor control. PLoS Biology, 2, e330. https://doi.org/10.1371/journal.pbio.0020330

Kotabe, H. P., \& Hofmann, W. (2015). On integrating the components of self-control. Perspectives on Psychological Science, 10, 618-638. https://doi.org/10.1177/1745691615593382

Kurzban, R. (2016). The sense of effort. Current Opinion in Psychology, 7, 67-70.

https://doi.org/10.1016/j.copsyc.2015.08.003

Kurzban, R., Duckworth, A. L., Kable, J. W., \& Myers, J. (2013). An opportunity cost model of subjective effort and task performance. The Behavioral and Brain Sciences, 36, 661-679. https://doi.org/10.1017/S0140525X12003196

Lieder, F., Shenhav, A., Musslick, S., \& Griffiths, T. (2018). Rational metareasoning and the plasticity of cognitive control. PLOS Computational Biology 14: e1006043.

https://doi.org/10.1371/journal.pcbi.1006043

Livneh, Y., Sugden, A. U., Madara, J. C., Essner, R. A., Flores, V. I., Sugden, L. A., ... \& Andermann, M. L. (2020). Estimation of current and future physiological states in insular cortex. Neuron. https://doi.org/10.1016/j.neuron.2019.12.027

Loewenstein, G. (1999). Because it is there: The challenge of mountaineering... for utility theory. Kyklos, 52, 315-343.

Ludyga, S., Gronwald, T., \& Hottenrott, K. (2016). The athlete's brain: Cross-sectional evidence for neural efficiency during cycling exercise. Neural Plasticity, 2016, 4583674.

https://doi.org/10.1155/2016/4583674

Manohar, S. G., Chong, T. T.-J., Apps, M. A. J., Batla, A., Stamelou, M., Jarman, P. R., . . Husain, M. (2015). Reward pays the cost of noise reduction in motor and cognitive control. Current Biology, 25, 1707-1716. https://doi.org/10.1016/i.cub.2015.05.038

Marcora, S. M. (2008). Do we really need a central governor to explain brain regulation of exercise performance? European Journal of Applied Physiology, 104, 929. https://doi.org/10.1007/s00421$\underline{008-0818-3}$

Marcora, S. M., Staiano, W., \& Manning, V. (2009). Mental fatigue impairs physical performance in humans. Journal of Applied Physiology, 106, 857-864. https://doi.org/10.1152/japplphysiol.91324.2008

Marcora, S. M., \& Staiano, W. (2010). The limit to exercise tolerance in humans: Mind over muscle? European Journal of Applied Physiology, 109, 763-770. https://doi.org/10.1007/s00421-010- 
Martin, K., Staiano, W., Menaspà, P., Hennessey, T., Marcora, S. M., Keegan, R., . . Rattray, B. (2016). Superior inhibitory control and resistance to mental fatigue in professional road cyclists. PloS One, 11, e0159907. https://doi.org/10.1371/journal.pone.0159907

Maxcy, J., Wicker, P., \& Prinz, J. (2019). Happiness as a reward for torture: Is participation in a longdistance triathlon a rational choice? Journal of Sports Economics, 20, 177-197. https://doi.org/10.1177/1527002518758144

McCormick, A., Meijen, C., Anstiss, P. A., \& Jones, H. S. (2018). Self-regulation in endurance sports: Theory, research, and practice. International Review of Sport and Exercise Psychology, 19, 1-30. https://doi.org/10.1080/1750984X.2018.1469161

McCormick, A., Meijen, C., \& Marcora, S. M. (2016). Psychological demands experienced by recreational endurance athletes. International Journal of Sport and Exercise Psychology, 6, 1-16. https://doi.org/10.1080/1612197X.2016.1256341

Melby-Lervag, M., \& Hulme, C. (2013). Is working memory training effective? A meta-analytic review. Developmental Psychology, 49, 270-291. https://doi.org/10.1037/a0028228.

Miller, E. K., \& Cohen, J. D. (2001). An integrative theory of prefrontal cortex function. Annual Review of Neuroscience, 24, 167-202. https://doi.org/10.1146/annurev.neuro.24.1.167

Missel, R. (2017, June 6). Cyclist quotes every rider should know. Bicycling. Retrieved March 24, 2020, from https://www.bicycling.com/news/g20042972/quotes-cyclists-should-know/

Morales-Alamo, D., Losa-Reyna, J., Torres-Peralta, R., Martin-Rincon, M., Perez-Valera, M., Curtelin, D., ... \& Calbet, J. A. (2015). What limits performance during whole-body incremental exercise to exhaustion in humans?. The Journal of Physiology, 593, 4631-4648.

https://doi.org/10.1113/JP270487

Monsell, S. (2003). Task switching. Trends in Cognitive Sciences 7, 134 - 140. https://dx.doi.org/10.1016/s1364-6613(03)00028-7

Morel, P., Ulbrich, P., \& Gail, A. (2017). What makes a reach movement effortful? Physical effort discounting supports common minimization principles in decision making and motor control. PLOS Biology, 15, e2001323. https://doi.org/10.1371/journal.pbio.2001323

Munakata, Y., Herd, S., Chatham, C., Depue, B., Banich, M., \& O'Reilly, R. (2011). A unified framework for inhibitory control. Trends in Cognitive Sciences 15, 453 - 459.

https://dx.doi.org/10.1016/j.tics.2011.07.011

Musslick, S., Cohen, J. D., \& Shenhav A. (2019). Decomposing individual differences in cognitive control: A model-based approach. Proceedings of the 41st Annual Conference of the Cognitive Science Society. Montreal, CA

Musslick, S., Jang, S.J., Shvartsman, M., Shenhav, A., \& Cohen, J.D. (2018). Constraints associated with cognitive control and the stability-flexibility dilemma. Proceedings of the 40th Annual Conference of the Cognitive Science Society. Madison, WI.

Musslick, S., Dey, B., Ozcimder, K., Patwary, M. M. A., Willke, T. L., Cohen, J. D. (2016). Controlled vs. automatic processing: a graph-theoretic approach to the analysis of serial vs. parallel processing in neural network architectures. Proceedings of the 38th Annual Conference of the Cognitive Science Society. Philadelphia, Pen. 
Musslick, S., Shenhav, A., Botvinick, M. M., \& Cohen, J. D. (2015). A computational model of control allocation based on the expected value of control. Reinforcement Learning and Decision Making Conference, Edmonton, Alberta, CA.

Neugebauer, V., Li, W., Bird, G. C., \& Han, J. S. (2004). The amygdala and persistent pain. The Neuroscientist, 10, 221-234. https://doi.org/10.1177/1073858403261077

Niendam, T. A., Laird, A. R., Ray, K. L., Dean, Y. M., Glahn, D. C., \& Carter, C. S. (2012). Meta-analytic evidence for a superordinate cognitive control network subserving diverse executive functions. Cognitive, Affective, \& Behavioral Neuroscience, 12, 241-268. https://doi.org/10.3758/s13415011-0083-5

Noakes, T. D., Peltonen, J. E., \& Rusko, H. K. (2001). Evidence that a central governor regulates exercise performance during acute hypoxia and hyperoxia. The Journal of Experimental Biology, 204, 3225-3234.

Pageaux, B. (2014). The psychobiological model of endurance performance: An effort-based decisionmaking theory to explain self-paced endurance performance. Sports Medicine, 44, 1319-1320. https://doi.org/10.1007/s40279-014-0198-2

Park, R. (2013, June 19). 50 best golf quotes of all time. Colorado Avid Golfer. Retrieved March 24, 2020, from https://coloradoavidgolfer.com/50-best-golf-quotes-of-all-time/

Périard, J. D., Pauw, K. de, Zanow, F., \& Racinais, S. (2018). Cerebrocortical activity during self-paced exercise in temperate, hot and hypoxic conditions. Acta Physiologica, 222. https://doi.org/10.1111/apha.12916

Perrey, S., \& Besson, P. (2018). Studying brain activity in sports performance: Contributions and issues. Progress in Brain Research, 240, 247-267. https://doi.org/10.1016/bs.pbr.2018.07.004

Phillips, J. M., Johnston, K., \& Everling, S. (2011). Effects of anterior cingulate microstimulation on pro-and antisaccades in nonhuman primates. Journal of Cognitive Neuroscience, 23, 481-490. https://doi.org/10.1162/jocn.2010.21482

Piper, S. K., Krueger, A., Koch, S. P., Mehnert, J., Habermehl, C., Steinbrink, J., ... \& Schmitz, C. H. (2014). A wearable multi-channel fNIRS system for brain imaging in freely moving subjects. Neuroimage, 85, 64-71. https://doi.org/10.1016/i.neuroimage.2013.06.062

Posner, M. I., \& Snyder, C. R. R. (1975). Attention and cognitive control. In R. L. Solso (Ed.) Information Processing and Cognition: The Loyola Symposium. Hillsdale, NJ: Erlbaum Assoc.

Radel, R., Brisswalter, J., \& Perrey, S. (2017). Saving mental effort to maintain physical effort: A shift of activity within the prefrontal cortex in anticipation of prolonged exercise. Cognitive, Affective \& Behavioral Neuroscience, 17, 305-314. https://doi.org/10.3758/s13415-016-0480-x

Richter, M., Gendolla, G. H. E., \& Wright, R. A. (2016). Three decades of research on motivational intensity theory. In A. J. Elliot (Ed.), Advances in Motivation Science (Vol. 3, pp. 149-186). Waltham: Elsevier Science/Academic Press. https://doi.org/10.1016/bs.adms.2016.02.001

Ritz, H., Frömer, R., \& Shenhav, A. (2020). Bridging Motor and Cognitive Control: It's About Time! Trends in Cognitive Sciences, 24(1), 6-8. https://doi.org/10.1016/j.tics.2019.11.005

Robazza, C., Bertollo, M., Filho, E., Hanin, Y., \& Bortoli, L. (2016). Perceived control and hedonic tone dynamics during performance in elite shooters. Research Quarterly for Exercise and Sport, 87, 284-294. https://doi.org/10.1080/02701367.2016.1185081 
Robertson, C. V., \& Marino, F. E. (2015). Prefrontal and motor cortex EEG responses and their relationship to ventilatory thresholds during exhaustive incremental exercise. European Journal of Applied Physiology, 115, 1939-1948. https://doi.org/10.1007/s00421-015-3177-x

Roloff, Z. A., Dicks, N. D., Krynski, L. M., Hartman, M. E., Ekkekakis, P., \& Pettitt, R. W. (2020). Ratings of affective valence closely track changes in oxygen uptake: Application to high-intensity interval exercise. Performance Enhancement \& Health, 100158.

https://doi.org/10.1016/i.peh.2020.100158

Rooks, C. R., Thom, N. J., McCully, K. K., \& Dishman, R. K. (2010). Effects of incremental exercise on cerebral oxygenation measured by near-infrared spectroscopy: A systematic review. Progress in Neurobiology, 92, 134-150. https://doi.org/10.1016/j.pneurobio.2010.06.002

Rupp, T., \& Perrey, S. (2008). Prefrontal cortex oxygenation and neuromuscular responses to exhaustive exercise. European Journal of Applied Physiology, 102, 153-163.

https://doi.org/10.1007/s00421-007-0568-7

Santos-Lozano, A., Collado, P., Foster, C., Lucia, A., \& Garatachea, N. (2014). Influence of sex and level on marathon pacing strategy. Insights from the New York City race. International Journal of Sports Medicine, 35, 933-938. https://doi.org/10.1055/s-0034-1367048

Schneider, W., \& Shiffrin, R. M. (1977). Controlled and automatic human information processing: I. Detection, search, and attention. Psychological Review, 84, 1-66. https://doi.org/10.1037/0033295X.84.1.1

Scholkmann, F., Kleiser, S., Metz, A. J., Zimmermann, R., Mata Pavia, J., Wolf, U., \& Wolf, M. (2014). A review on continuous wave functional near-infrared spectroscopy and imaging instrumentation and methodology. Neurolmage, 85, 6-27. https://doi.org/10.1016/j.neuroimage.2013.05.004

Secher, N. H., Seifert, T., \& Van Lieshout, J. J. (2008). Cerebral blood flow and metabolism during exercise: Implications for fatigue. Journal of Applied Physiology, 104, 306-314.

https://doi.org/10.1152/japplphysiol.00853.2007

Seidel, O., Carius, D., Roediger, J., Rumpf, S., \& Ragert, P. (2019). Changes in neurovascular coupling during cycling exercise measured by multi-distance fNIRS: A comparison between endurance athletes and physically active controls. Experimental Brain Research, 237, 2957-2972.

https://doi.org/10.1007/s00221-019-05646-4

Shackman, A. J., Salomons, T. V., Slagter, H. A., Fox, A. S., Winter, J. J., \& Davidson, R. J. (2011). The integration of negative affect, pain and cognitive control in the cingulate cortex. Nature Reviews Neuroscience, 12, 154-167. https://doi.org/10.1038/nrn2994

Shadmehr, R., Huang, H. J., \& Ahmed, A. A. (2016). A representation of effort in decision-making and motor control. Current Biology, 26, 1929-1934. https://doi.org/10.1016/j.cub.2016.05.065

Schaefer, S., \& Scornaienchi, D. (2020). Table tennis experts outperform novices in a demanding cognitive-motor dual-task situation. Journal of Motor Behavior, 52, 204-213. https://doi.org/10.1080/00222895.2019.1602506

Shenhav, A., Botvinick, M. M., \& Cohen, J. D. (2013). The expected value of control: An integrative theory of anterior cingulate cortex function. Neuron, 79, 217-240. https://doi.org/10.1016/i.neuron.2013.07.007

Shenhav, A., Cohen, J. D., \& Botvinick, M. M. (2016). Dorsal anterior cingulate cortex and the value of control. Nature Neuroscience, 19, 1286-1291. https://doi.org/10.1038/nn.4384 
Shenhav, A., Musslick, S., Lieder, F., Kool, W., Griffiths, T. L., Cohen, J. D., \& Botvinick, M. M. (2017). Toward a rational and mechanistic account of mental effort. Annual Review of Neuroscience, 40, 99-124. https://doi.org/10.1146/annurev-neuro-072116-031526

Sherrington, C., Tiedemann, A., Fairhall, N., Close, J. C., \& Lord, S. R. (2011). Exercise to prevent falls in older adults: An updated meta-analysis and best practice recommendations. New South Wales Public Health Bulletin, 22, 78-83. https://doi.org/10.1071/NB10056

Smyth, B. (2018). Fast starters and slow finishers: A large-scale data analysis of pacing at the beginning and end of the marathon for recreational runners. Journal of Sports Analytics, 4, 229242. https://doi.org/10.3233/JSA-170205

Staiano, W., Bosio, A., de Morree, H. M., Rampinini, E., \& Marcora, S. (2018). The cardinal exercise stopper: Muscle fatigue, muscle pain or perception of effort? In Progress in Brain Research (Vol. 240, pp. 175-200). Elsevier. https://doi.org/10.1016/bs.pbr.2018.09.012

Stets, A., Smith, S. L., \& Helton, W. S. (2019). Dual-task interference between swimming and verbal memory. Human Factors, 18720819871743. https://doi.org/10.1177/0018720819871743

Stork, M. J., Graham, J. D., Bray, S. R., \& Martin Ginis, K. A. (2016). Using self-reported and objective measures of self-control to predict exercise and academic behaviors among first-year university students. Journal of Health Psychology, 1-11. https://doi.org/10.1177/1359105315623627

Strait, C. E., Blanchard, T. C., \& Hayden, B. Y. (2014). Reward value comparison via mutual inhibition in ventromedial prefrontal cortex. Neuron, 82, 1357-1366.

https://doi.org/10.1016/i.neuron.2014.04.032

Strangman, G., Culver, J. P., Thompson, J. H., \& Boas, D. A. (2002). A quantitative comparison of simultaneous BOLD fMRI and NIRS recordings during functional brain activation. Neurolmage, 17, 719-731. https://doi.org/10.1006/nimg.2002.1227

Ullsperger, M., Danielmeier, C., \& Jocham, G. (2014). Neurophysiology of performance monitoring and adaptive behavior. Physiological Reviews, 94, 35-79.

https://doi.org/10.1152/physrev.00041.2012

Walsh, V. (2014). Is sport the brain's biggest challenge? Current Biology, 24, 859-60. https://doi.org/10.1016/i.cub.2014.08.003

Westbrook, A., \& Braver, T. S. (2015). Cognitive effort: A neuroeconomic approach. Cognitive, Affective, \& Behavioral Neuroscience, 15, 395-415. https://doi.org/10.3758/s13415-015-0334-y

Wingfield, G., Marino, F., \& Skein, M. (2018). The influence of knowledge of performance endpoint on pacing strategies, perception of effort, and neural activity during $30-\mathrm{km}$ cycling time trials. Physiological Reports, 6, e13892. https://doi.org/10.14814/phy2.13892

Wolff, W. (2017). Funktionelle Nahinfrarotspektroskopie in der sportpsychologischen Forschung. Zeitschrift für Sportpsychologie, 24, 17-28. https://doi.org/10.1026/1612-5010/a000184

Wolff, W., Baumann, L., \& Englert, C. (2018). Self-reports from behind the scenes: Questionable research practices and rates of replication in ego depletion research. PLOS ONE, 13, e0199554. https://doi.org/10.1371/journal.pone.0199554

Wolff, W., Bertrams, A., \& Schüler, J. (2019). Trait self-control discriminates between youth football players selected and not selected for the German talent program: A Bayesian analysis. Frontiers in Psychology, 10, 2203. https://doi.org/10.3389/fpsyg.2019.02203 
Wolff, W., Bieleke, M., \& Schüler., J. (2019). Goal-striving and endurance performance. In C. Meijen (ed.), Endurance performance in sport: Psychological Theory and Interventions. London: Routledge.

Wolff, W., Bieleke, M., Hirsch, A., Wienbruch, C., Gollwitzer, P. M., \& Schüler, J. (2018). Increase in prefrontal cortex oxygenation during static muscular endurance performance is modulated by self-regulation strategies. Scientific Reports, 8, 15756. https://doi.org/10.1038/s41598-018$\underline{34009-2}$

Wolff, W., Martarelli, C. (2020). Bored into depletion? Towards a tentative integration of perceived self-control exertion and boredom as guiding signals for goal-directed behavior. Perspectives on Psychological Science, 15(5):1272-1283. https://doi.org/10.1177/1745691620921394

Wolff, W., Martarelli, C., Schüler, J., \& Bieleke, M. (2020). High boredom proneness and low trait selfcontrol impair adherence to social distancing guidelines during the COVID-19 pandemic. Int. J. Environmental Research and Public Health, 17. https://doi.org/10.31234/osf.io/icf95

Wolff, W., Schüler, J., Hofstetter, J., Baumann, L., Wolf, L., \& Dettmers, C. (2019). Trait self-control outperforms trait fatigue in predicting MS patients' cortical and perceptual responses to an exhaustive task. Neural Plasticity, 2019, 8527203. https://doi.org/10.1155/2019/8527203

Wolff, W., Sieber, V., Bieleke, M., \& Englert, C. (2019). Task duration and task order do not matter: no effect on self-control performance. Psychological Research. https://doi.org/10.1007/s00426-01901230-1

Wolff, W., Thürmer, J. L., Stadler, K.-M., \& Schüler, J. (2019). Ready, set, go: Cortical hemodynamics during self-controlled sprint starts. Psychology of Sport and Exercise, 41, 21-28. https://doi.org/10.1016/i.psychsport.2018.11.002

Wright, R. A., Mlynski, C., \& Carbajal, I. (2019). Outsiders' thoughts on generating self-regulatorydepletion (fatigue) effects in limited-resource experiments. Perspectives on Psychological Science, 14, 469-480. https://doi.org/10.1177/1745691618815654

Yang, J., Park, K., \& Shin, M. (2019). Effects of ego-depletion and state anxiety on performance changes in dart-throwing tasks: A latent curve model approach reporting trial data for human participants. Frontiers in Psychology, 10, 2027. https://doi.org/10.3389/fpsyg.2019.02027

Zengzhi Guo, Ting Ma, \& Fei Chen (2019, March). Effects of grip-load force and muscle fatigue on fNIRS signal during handgrip voluntary contraction task. $9^{\text {th }}$ International IEEE EMBS Conference on Neural Engineering, San Francisco, CA, USA. 